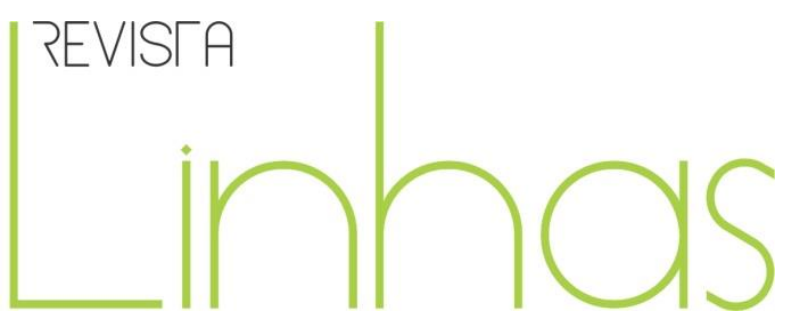

\title{
O flâneur e as vertigens do tempo: uma aprendizagem
}

\section{Resumo}

De todas as imagens que fazem parte da vida contemporânea, a ideia de trânsito parece ser uma das principais. Diante de um mundo marcado pela velocidade e interação contínuas, a passagem entre-lugares assume um importante estatuto. Todavia, quando esse ir e vir torna-se, ele, o território, a existência passa a ser vertiginosa. Vertigens do tempo e de espaços, de tempos que se sobrepõem e de espaços pouco capturáveis. O flâneur, essa espécie de anti-herói anunciada por Charles Baudelaire, é reassumido neste texto, sugerindo pistas acerca de como situar-se diante disto que incessantemente foge. Com Henry Miller, escritor americano, o ato de caminhar é problematizado, um transitar não somente por lugares, mas, sobretudo, por tempos e pela multiplicidade de vidas engendradas numa vida. Ainda que circunscrita a uma realidade urbana do século XIX, talvez ainda haja algo a aprender com o ato de flanar.

Palavras-chave: Baudelaire, Charles. 1821-1867. Miller, Henry, D. Espaço e Tempo.

\section{Para citar este artigo:}

MUNHOZ, Angelica Vier; DA COSTA, Luciano Bedin. O flâneur e as vertigens do tempo: uma aprendizagem.

Revista Linhas. Florianópolis, v. 18, n. 38, p. 292-303, set./dez. 2017.

\author{
Angelica Vier Munhoz \\ Centro Universitário Univates - \\ Brasil \\ angelicavmunhoz@gmail.com \\ Luciano Bedin da Costa \\ Universidade Federal do Rio \\ Grande do Sul - UFRS - Brasil \\ bedincosta@gmail.com
}




\title{
The flâneur and the vertigos of time: a learning experience
}

\begin{abstract}
Among all the images that are part of contemporary life, the idea of transit seems to be one of the main. In the face of a world marked by speed and continuous interaction, the crossing between-places assumes an important statute. However, when this going and coming becomes itself a territory, existence turns vertiginous. Vertigos of time and spaces, of times that superpose and spaces that are difficult to capture. The flâneur, this kind of anti-hero announced by Charles Baudelaire, is restored in this text, suggesting ways of positioning oneself before that which incessantly runs away. With Henry Miller, the American writer, the act of walking is discussed, a transiting not only in places, but especially in times and in the multiplicity of lives engendered within one life. Even being restricted to the urban reality of the nineteenth century, maybe there is something to learn with the act of flâneuring.
\end{abstract}

Keywords: Baudelaire, Charles. 1821-1867. Miller, Henry, D. Space and Time. 
Multidão, solidão: termos iguais e permutáveis para o poeta ativo e fecundo. Quem não sabe povoar sua solidão, tampouco sabe estar só em meio a uma massa atarefada.

(Charles Baudelaire)

Em nossas bocas, um enunciado recorrente: vivemos uma época de interação. Quer gostemos ou não, somos constantemente atirados a uma grande teia de relações que ultrapassa domínios até pouco tempo inimagináveis. As linhas que tecem nossa vida cotidiana, outrora devidamente instauradas no espaço da família, trabalho, escola, hoje se entrecruzam em segmentações cada vez mais fluidas, sutis e epidêmicas. Nossos territórios tornam-se incessantemente moventes, num plano em que virtualidades convivem com altas velocidades, jogando-nos para além de nós mesmos. O sujeito outrora confiante em si e "responsável" pela sua trajetória - dilui-se, escorrendo para diferentes espaços e tempos. Ele confortavelmente se senta em frente ao computador e observa o perfil por ele criado em sites de relacionamento. A cada acesso diário, sua rede de relações se vê estendida e disposta de forma diferente. Novos amigos que chegam, comentários, mensagens recebidas, compartilhamento de imagens, etc. O sujeito é tragado para territórios que se movimentam - e que o movimentam - em espaços fragmentários e absurdamente rizomáticos. A experiência da convivência ganha novas dimensões nesta extrapolação dos contornos. O sujeito está ali onde tudo parece estar no mesmo lugar e que ao mesmo tempo não cessa de se movimentar. Neste jogo de presença-ausência, de movimento-retidão, a experiência do tempo passa a ter a marca deste estranho paradoxo. A vertigem passa a ser a assinatura e a condição de vida. Mas podemos, nós, reter deste fluxo passante que atropela nossos contornos a todo instante? É possível, nesta história que incessantemente nos foge, encontrarmos pistas acerca de como nos deslocarmos sem sermos arrastados por este tsunami de deslocamentos chamado contemporâneo? Trataremos, então, de buscar algumas imagens em dois escritores que viveram e anunciaram a modernidade: Charles Baudelaire e Henry Miller. 


\section{Baudelaire e os desacordos da modernidade}

Charles Baudelaire (1821-1867) é conhecido como o poeta da modernidade. E tal afirmação se justifica, pois Baudelaire é um dos criadores dessa palavra, empregando-a, em 1859, para expressar o particular do artista moderno, "a capacidade de ver no deserto da metrópole não só a decadência do homem, mas também de pressentir uma beleza misteriosa, não descoberta até então" (FRIEDRICH, 1991, p. 35). Apossando-se desses elementos, Baudelaire valorava essa decadência, da qual ele, como moderno, era testemunha (BENJAMIN, 2000).

É nesse sentido que Baudelaire faz do conceito de modernidade algo dissonante. A decadente metrópole ferida pelo fetiche da mercadoria e pelo capitalismo burguês oferece matérias estimulantes para serem apreendidas poeticamente: o odor de alcatrão se mistura ao perfume das flores, a luz ofuscante se junta ao crepúsculo. O desacordo da "nova" cidade torna-se, então, intensidade vivida pelo poeta. Aos olhos de Baudelaire, a cidade sólida e inabalável torna-se fluida e volúvel, sujeita a transformações e imprevisibilidades. A transformação da cidade torna-se, para Baudelaire, sinônimo da produção do moderno.

Andrômaca, só penso em ti! O fio d'água Soturno pobre espelho onde esplendeu outrora

De tua solidão de viúva a imensa mágoa, Este mendaz Simeonte, em que teu pranto aflora

Fecundou-me de súbito a fértil memória Quando eu cruzava a passo o novo carrossel Foi-se a velha Paris (de uma cidade a história)

Depressa muda mais que um coração infiel)

(BAUDELAIRE, 2006, p. 301)

Um outro título coube a Baudelaire: o de homem das multidões. "Povoar sua solidão" e "estar só em meio a uma massa atarefada" (BAUDELAIRE, 2009, p. 10) são dois movimentos que se sucedem, na obra do poeta. A multidão é o seu domínio, sua profissão, emancipação de suas experiências vividas. Mas, embora Baudelaire buscasse inspiração para o tema da multidão na novela de Poe (O homem da multidão - da qual faz a tradução), a multidão de transeuntes de Londres não é a multidão de Baudelaire. 0 homem da multidão de Baudelaire é o flâneur parisiense. E o flâneur é "ao mesmo tempo, 
a multidão que ele contempla e o desconhecido nessa multidão" (BAUDELAIRE, 2009, p. 120).

Assim, o flâneur é uma figura privilegiada para pensar a cidade e a modernidade, as condições de produções literárias e o papel do artista nesse contexto. Essa errante figura denuncia o nascimento de um novo tipo de experiência de vida, de tempo e de espaço. E Baudelaire nos mostra esse contraponto: o fenômeno urbano das multidões e a experiência vivida em sua nudez, na experiência do passante.

Todavia, é através do olhar do flâneur que a cidade de Paris é transfigurada poeticamente por Baudelaire, em seu estado de spleen". "E Paris (...), é mais (ou menos) que uma cidade: é, como vimos, um estado mental" (BAUDELAIRE, 2009, p. 16). A cidade é, pois, a paisagem para o flâneur, a rua, sua moradia, lugar no qual ele é conduzido ao “tempo desaparecido". Ao vagar pelas ruas, apreendendo a cada detalhe sem ser notado e sem se inserir na paisagem, o flâneur quer apossar-se de sua própria experiência. Mas tal experiência parece esvaziar-se diante das multidões de seu tempo. A cidade superpovoada, os espaços preenchidos, os movimentos dos transeuntes compõem a multidão. E o homem da multidão recusa-se a estar só. Está em todos os lugares enquanto está em lugar nenhum. "A maior parte dos que passavam tinha o aspecto de gente satisfeita consigo mesma e solidamente instalada na vida. Parecia que pensavam apenas em abrir caminho por entre a multidão..." (BENJAMIN, 2000, p. 72).

Atento às multidões de seu tempo, mas alheio à inevitável urbanização das cidades, o flâneur busca encontrar seus espaços vazios, porém o ritmo com que as pessoas se movem e o ultrapassam, o ultrajam. Ele necessita do espaço, pois não quer renunciar a sua vida privada e afunda-se no âmago da experiência, no qual o aroma é o seu principal refúgio. Com lentidão, ele se desloca desejando que o progresso também se movimente ao seu próprio ritmo. Contudo, a multidão é a usina do flâneur. Ao se mover com desenvoltura entre as multidões, o flâneur vê na multidão o lugar do anonimato, do refúgio, da contemplação da diversidade. Experiência de quem não deve satisfação ao seu tempo enquanto busca na rua a fonte de sua inspiração. “A beleza pura é única; a luz

\footnotetext{
${ }^{1}$ Esta palavra remete a um "tédio existencial”, mas como afirma Dirceu Villa, na introdução de Baudelaire: pequenos poemas em prosa, é um "termo tão específico e difícil de traduzir que Baudelaire, como tantos outros, preferiu deixar mesmo em inglês, assinalando não só o que queria dizer com a palavra específica, mas também sua filiação." (BAUDELAIRE, 2009, p. 15)
} 
é o ideal de qualquer vida. A expressão do belo, fenômeno da vida, é uma variável ligada ao tempo, ao clima, ao lugar..." (DUFILHO, 2010, p. 110).

Sob a aparência de uma olhar distraído, esconde-se a volúpia do flâneur, cuja obstinação consiste na decifração de signos, na busca de imagens vivas, no encontro de paisagens em movimento, nos vestígios de uma aura, no fascínio de um olhar. Dar alma a uma multidão vivaz, enquanto amante da vida, constitui a verdadeira experiência do tempo para Baudelaire. Uma experiência povoada de sentidos.

Não é dado a qualquer um tomar banho de multidão. Desfrutar da massa é uma arte e só poderá fazer, às custas do gênero humano, uma orgia de vitalidade, aquele a quem uma fada terá insuflado no berço o gosto pelo disfarce e a máscara, o ódio do domicílio e a paixão pela viagem. (BAUDELAIRE, 2009, p. 69)

Se por um lado a figura do flâneur nos reporta ao âmago da experiência vivida, por outro, nos remete à concretização da perda da experiência do tempo. Esse tempo, que levou ao esquecimento as duas maiores invenções da humanidade - o passado e o futuro - produziu também a degradação da experiência o "caráter medíocre e raso da experiência" (NOVAES, 2010). A experiência do homem moderno do século XIX, marcado, segundo Benjamin (2000), pelo tédio e pela melancolia, contribuiu para a única experiência possível - a experiência vazia de sentidos, efeito da transfiguração do tempo e do espaço.

O spleen oferece a Baudelaire a reflexão sobre o distanciamento entre o passado e o presente e a impossibilidade da experiência que se mostra através do enfraquecimento da memória. A imobilização do tempo e a busca incessante do novo movem também 0 pintor da vida moderna - outra forma encontrada por Baudelaire para registrar, a partir dos desenhos de Constatin Guys, a destruição e o perecimento, ou seja, a força de envelhecimento de uma modernidade que se engendra a todo o momento como busca da novidade. Como disse Benjamin, "Aquilo que sabemos que, em breve, já não teremos diante de nós torna-se imagem" (BENJAMIN, 1991, p. 85).

Baudelaire nos aponta para o reconhecimento desse desencanto da experiência autêntica: “Digamos que eu tenha trinta anos, mas se vivi três minutos em um..., não tenho noventa anos?" (BAUDELAIRE, 2009a, p. 32). 


\section{Henry Miller e o caminhar por entre-vidas}

Henry Miller (1891-1980), um dos maiores escritores americanos, tornou-se notável pela íntima relação entre vida e literatura. Sua escritura autobiográfica revela aspectos do modo como conduziu sua vida, resultando numa obra híbrida e bastante singular. A verdade da experiência vivida encontra ecos na ficção literária, tornando-se difícil (ou inútil) estabelecer alguma distinção entre um e outro. O personagem dos livros atende em primeira pessoa, narrando experiências do escritor. Trata-se, segundo Ferguson (1991, p. 16), de uma bibliomorfose, do fenômeno de criação de um ser que é, ao mesmo tempo, um híbrido raro de homem e livro. "Ele acreditava de todo coração que pertencia a si mesmo, e que pertencer a si mesmo lhe dava o direito de inventar a si mesmo" (FERGUSON, 1991, p. 17). A reinvenção autobiográfica de Henry Miller inviabiliza a reconstrução do homem verídico Henry Miller. Ao escrever sua vida, Miller rebatiza esta mesma vida, atribuindo ao real os pormenores fabulatórios de sua atividade de escritura. Os nomes e datas são embaralhados, ganham novas dimensões e se deslocam na superfície do texto. Se há uma ética na escritura milleriana, esta está relacionada à ideia de movimento. "A gente passa imperceptivelmente de uma cena, de uma idade, de uma vida para outra" (MILLER, 1968, p. 19).

De todos os livros de Henry Miller, Primavera Negra (1936) talvez seja aquele em que a figura do caminhante se mostra mais evidente. Apaixonado pelo surrealismo de André Breton, Henry Miller se põe a registrar os movimentos de espaço-tempo como uma espécie de datilógrafo flâneur. Os capítulos que compõem o livro são recheados de fragmentos dispersos que afirmam a atividade deambulatória de Miller por entre os lugares de sua infância no Décimo-Quarto Distrito do Brooklyn e pelos itinerários de sua vida posterior. A rua torna-se uma espécie de totem: a rua por onde as primeiras lembranças de infância são acionadas, a rua por onde o escritor anuncia o homem que virá a ser e a rua na qual as vivências da vida adulta serão efetivadas. "Ter nascido na rua significa vaguear toda a vida, ser livre. Significa acidente e incidente, drama, movimento. Significa acima de tudo, sonho" (MILLER, 1968, p. 15). No espaço de grandes avenidas e ruelas, no exíguo trajeto de uma ponte, a vida se vê confrontada com a dureza do real e as artimanhas do onírico. O drama milleriano passa por forças alimentadas pelo comum e ordinário dos passantes, por personagens que, em muitas vezes, não reservam nada além 
de suas próprias miserabilidades. Aquele que deambula captura signos mundanos, devolvendo-os à página do livro de forma transubstanciada. "As coisas estão acontecendo em toda a volta. A tensão de esperar que alguma coisa aconteça é algo delirante" (MILLER, 1968, p. 105). O flâneur milleriano reserva também para si a nobre habilidade de ficar à espreita.

Deus sabe que já vivi em Paris o tempo suficiente para não me sentir surpreendido como coisa alguma. Aqui não é necessário procurar deliberadamente por aventuras, tal como acontece em Nova lorque... só é preciso ter um pouco de paciência e aguardar; a vida virá ao nosso encontro nos locais mais incríveis e obscuros e as coisas se passam aí. (MILLER, 1985, p. 13)

Mas a bibliomorfose autobiográfica milleriana não se destina apenas aos contornos de si; ao colocar o vivido na lisa superfície do texto, fabula-se também a imensa coleção de nomes, datas e lugares que numa vida se atravessam. "Uma harmonia de fatos irrelevantes que dá à perambulação da gente uma certeza metafísica" (MILLER, 1968, p. 15). Todavia, a metafísica milleriana encontra-se devidamente untada pela imanência dos acontecimentos. Os tais fatos irrelevantes, outrora colocados à margem de uma história majoritária, são para Miller o tutano de sua própria estrutura narrativa. 0 escritor caminha por entre as brechas da história; encontra patas para caminhar por todas as direções e sentidos. "Eu sou o cancro, o caranguejo que se move de lado, para trás e para frente à vontade" (MILLER, 1968, p. 34). A experiência milleriana é da ordem destes lentos e ágeis pés - uma lentidão capaz de capturar as mínimas nuances do vivido e a agilidade para lidar com as voltas e atletismos dos acontecimentos.

Daqui por diante caminhamos divididos em miríades de fragmentos, como um inseto com uma centena de pés, uma centopéia de pés macios e ágeis que bebe na atmosfera; caminhamos com filamentos sensíveis que bebem avidamente passado e futuro, e todas as coisas fundem-se em música e tristeza; caminhamos contra um mundo unido, afirmando nossa desunião. (MILLER, 1968, p. 20)

Diante de um mundo regido por incoerências e paradoxos, a sinceridade só pode ser sustentada pela composição de lados aparentemente opostos num mesmo plano. 0 flâneur datilografa sua mais absoluta verdade. Todavia, a experiência do verdadeiro é a 
experiência da verdade capturada no exato instante em que a intensidade clama por expressão. Trata-se daquilo que Nietzsche (2007, p. 46) chama de um outro tipo de verdade: "há forças terríveis que Ihe irrompem constantemente e que opõem às verdades científicas verdades de um tipo totalmente diferente, com as mais diversas espécies de emblemas". Como a própria rua e seus passantes, a verdade milleriana caminha ao sabor dos insólitos encontros, vendo-se constantemente assediada pelo hálito da ficção. O flâneur datilografa permanências em suas próprias incoerências.

Para mim o livro é o homem e meu livro é o homem que eu sou, o homem confuso, o homem negligente, o homem imprudente, o homem sadio, obsceno, impetuoso, pensativo, escrupuloso, mentiroso, diabolicamente verdadeiro que sou. (MILLER, 1968, p. 30)

Ao trabalhar com a matéria de um vivido, o flâneur se põe a registrar signos de memória e, sobretudo, de esquecimento. Aquilo que captura tem a marca do reconhecível, do cognoscível, daquilo que se presta ao reconhecimento por parte de suas faculdades mentais. Todavia, poeticamente engajado à insólita proposta de se mostrar poroso às coisas que passam, ele se vê diante de uma encruzilhada: aceitá-las, as coisas, é aceitar sua própria volatilidade, afirmar a impossibilidade de retê-las da forma como elas se apresentam. Os passos do flâneur arrastam abolições. A experiência é a experiência de abolição dos objetos em sua integralidade - só haverá, pois, objetos parciais. Trata-se, pois: 1) da abolição da história em seu finalismo e linearidade - não haverá, pois, motivos óbvios e causas evidentes para os acontecimentos; 2) da abolição do sujeito como gerenciador e único doador de sentido do mundo - nesta teia de coisas que acontecem, ele é apenas mais uma coisa a acontecer. De toda forma, resta-nos a pergunta: abolir e abolir-se para quê? De que estaria a serviço a abolição do sujeito ou do mundo em sua integralidade? A literatura de Miller nos dá pistas acerca deste procedimento, jogandonos, não para um niilismo - no qual nada teria valor ou serviria - mas a uma nuvem de virtualidades sob a qual devires não efetivados insinuam-se e pedem corpo para novas atualizações. "Há enormes blocos de minha vida que sumiram para sempre. Enormes blocos sumidos, dispersados, desperdiçados em conversa, ação, reminiscência, sonho" (MILLER, 1968, p. 34). Mas o que se dispersa, esta matéria fragmentária em dispersão, não retorna senão como diferença. Ali onde o fantasma da experiência de integralidade 
nunca põe as mãos - afinal, a ilusão de captura do acontecimento em sua completude é uma armadilha da memória - é onde a diferença retorna sempre como signo novidadeiro ou fiapo a-significante. Vive-se, pois, na suposta vida já vivida, outras vidas. Os componentes podem ser os mesmos - a mesma rua, os mesmos carros, os mesmos amores - mas as relações serão sempre diversas. "Jamais houve época em que eu estivesse vivendo uma só vida, a vida de um marido, de um amante, de um amigo. Onde quer que eu estivesse, no que quer que eu estivesse empenhado, eu levaria vidas múltiplas" (MILLER, 1968, p. 34). Na experiência do encontro, o outro joga-nos para a estranha superfície de alteridade diante de nós mesmos. Tornamo-nos outros na experiência com estes outros que nos entornam e nos assediam. Será, pois, do lugar do outro que enunciamos nossa voz, que rabiscamos nossas folhas, que transitamos pelos comuns dos lugares e territórios.

Caminhando sobre a ponte de Brooklyn... É isto o mundo, este caminhar para cima e para baixo, estes edifícios que estão iluminados, os homens e mulheres que passam por mim? Observo seus lábios movendo-se, os lábios dos homens e mulheres que passam por mim. Sobre o que estão falando - alguns deles tão seriamente? Odeio ver gente tão mortalmente séria quando eu próprio estou sofrendo mais do que qualquer um deles. Uma vida só! E há milhões de vidas para serem vividas! (MILLER, 1968, 107)

\section{Por falar em flanar...}

A experiência do tempo na contemporaneidade é muito diferente da experiência do tempo no século XX. O "tempo homogêneo e vazio" apontado por Benjamin (2000) vive hoje talvez a sua maior radicalidade. A temporalidade contemporânea, constituída pela passagem de um mundo com regras conhecidas para um mundo incerto e absolutamente instável, produz não mais o tédio, mas a monotonia (MATOS, 2008). O tédio para Baudelaire é a temporalidade do passado que se repete continuamente no presente, mas sem perda do futuro. Já a monotonia é um tempo estagnado, patológico, vazio de significado, temporalidade alienada. Esse tempo promete a felicidade pelo consumo de bens materiais, mas permanentemente frustra essa esperança, pois não é possível, em regime de acúmulo, reposição e acréscimo do capital, democratizar o 
excedente e o supérfluo (MATOS, 2008). Assim, na era da mutação tecnocientífica, temos o elogio do presente eterno, este exigindo absoluta supremacia diante do passado e do futuro. Tudo se torna veloz, efêmero e volátil. Perdemos assim a experiência da história, a lentidão, a captura do olhar, o tempo da vida vivida. A experiência - jogada a níveis e velocidades absurdas - é reduzida ao mínimo de sentido, ou ao sentido do instante, o que seria quase uma ausência da experiência. Movidos pela ciência e pela técnica, abdicamos do movimento de experimentar o mundo e experienciar a si mesmo. A "passagem" torna-se moeda de troca - é preciso, pois, passar pelas coisas, passar pelas sensações, passar pelos sentimentos, passar pelas experiências - sem deixar que estas passagens nos atravessem. Na teia de fluxos e capturas do contemporâneo é desinteressante que algo fique retido por muito tempo. O olhar desacostuma-se com o ínfimo que se passa e tudo passa como se olhássemos da janela de um avião a jato: a alturas e velocidades absurdas, a paisagem parece estática (SANT'ANNA, 2001). Talvez ainda haja algo a aprender com a figura do flâneur, com essas coisas que exigem da vida outros movimentos. Nietzsche (1995, p. 38) escreve: “Ficar sentado o menor tempo possível; não dar crença ao pensamento, não nascido ao ar livre, de movimentos livres - no qual também os músculos não festejem." Ao final das contas, trata-se de jogar o suposto simplório cotidiano ao mistério das coisas ainda não efetivadas. Um olhar, uma microexperiência de deslocamento naquilo que parece mais domesticado pela maquinaria contemporânea dos sentidos. É como Henry Miller bem nos adverte: (1968, p. 154): "Ora, eu saí para um passeio, um curto passeio de cinquenta anos mais ou menos efetuado no virar de uma página".

\section{Referências}

BAUDELAIRE, Charles. Pequenos poemas em prosa (O spleen de Paris). $2^{a}$ ed. Tradução Dorothée de Bruchard. São Paulo: Hedra, 2009. 251 p.

BAUDELAIRE, Charles. Meu coração desnudado. $1^{\text {a }}$ ed. Tradução e notas Tomaz Tadeu. Belo Horizonte: Autêntica, 2009a. 147 p.

BAUDELAIRE, Charles. As flores do mal. Rio de Janeiro: Nova Fronteira, 2006. 653 p. 
BENJAMIN, Walter. A modernidade e os modernos. $2^{\mathrm{a}}$ ed. Tradução Heindrun K. M. da Silva et al. Rio de Janeiro: Tempo Brasileiro, 2000. 108 p.

BENJAMIN, Walter. Obras escolhidas III: Charles Baudelaire, um lírico no auge do capitalismo. São Paulo: Brasiliense, 1991.

DUFILHO, Jérôme. O pintor e o poeta. In: DUFILHO, Jérôme e TADEU, Tomaz (Orgs). Charles Baudelaire: o pintor da vida moderna. 1 ed. Belo Horizonte: Autêntica, 2010. 151 p.

FERGUSON, Robert. Henry Miller: uma vida. Tradução Magda Lopes. Porto Alegre: L\&PM, 1991. $432 \mathrm{p}$.

FRIEDRICH, Hugo. Estrutura da lírica moderna. $2^{a}$ ed. Tradução Marise M. Curioni. São Paulo: Duas cidades, 1991. 349 p.

MATOS, Olgária. O mal-estar na contemporaneidade: performance e tempo. ComCiência, Campinas, n. 101, 2008. Disponível em

<http://comciencia.scielo.br/scielo.php?script=sci_arttext\&pid=S1519

$76542008000400008 \&$ Ing=pt\&nrm=iso $>$. acessos em 07 out. 2013.

MILLER, Henry. Opus Pistorum. Tradução José Jacinto da Silva Pereira. Lisboa:

Publicações Dom Quixote, 1985. 278 p.

MILLER, Henry. Primavera Negra. Tradução Aydano Arruda. São Paulo: IBRASA, 1968. $195 \mathrm{p}$.

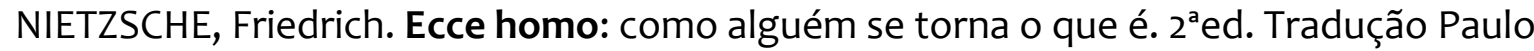
César de Souza. São Paulo: Companhia das Letras, 1995. 153 p.

NIETZSCHE, Friedrich. Sobre verdade e mentira. Tradução Fernando de Moares Barros. São Paulo: Hedra, 2007. 95 p.

NOVAES, Adauto. O espírito recusa a habitar a sua obra. In: NOVAES, Adauto (Org.). A experiência do pensamento. $1^{a}$ ed. São Paulo: Edições SESC SP, 2010. 432p.

SANT'ANNA, Denise. Corpos de passagem: ensaios sobre a subjetividade contemporânea. 1 Ed. São Paulo: Estação Liberdade, 2001. 127p.

Recebido em: 24/12/2015 Aprovado em: 25/08/2016

Universidade do Estado de Santa Catarina - UDESC Programa de Pós-Graduação em Educação - PPGE Revista Linhas

Volume 18 - Número 38 - Ano 2017 revistalinhas@gmail.com 